\title{
Trudy Govier and Premise Adequacy
}

\section{DEREK ALLEN}

\author{
Department of Philosophy \\ University of Toronto \\ 170 St. George St. \\ Toronto, $O N$ \\ Canada M5R $2 M 8$ \\ derekallen@trinity.utoronto.ca
}

\begin{abstract}
My main concern in this paper is with Trudy Govier's acceptability criterion for the adequacy of the premises of an argument considered independently of whether they are "properly connected" to the conclusion. I consider arguments she makes against the view that a good argument must have true premises, and I contend that a theory of argument could hold both that for an argument to be a good argument its premises must be true and that for it to be a good argument relative to its audience, the audience must be epistemically justified in accepting its premises as true.
\end{abstract}

Résumé: Ma préoccupation principale dans cet article est le critère d'acceptabilité de Trudy Govier appliqué aux prémisses examinées indépendamment de leur appui pour leur conclusion. J'évalue ses arguments contre l'idée qu'un bon argument doit avoir des prémisses vraies, et je soutiens qu'une théorie de l'argumentation pourrait proposer à la fois qu'un bon argument doit avoir des prémisses vraies et qu'un auditoire qui juge qu'un argument est bon doit être épistémiquement justifié pour accepter que ses prémisses sont vraies.

Keywords: Trudy Govier, acceptable, epistemically justified, false, premise adequacy, true, unacceptable.

\section{Introduction}

It is a privilege to contribute to this special issue of Informal Logic in honour of Trudy Govier. Trudy has been a central figure in the field of informal logic for many years; indeed, she has helped to create and define the field as one of serious scholarly and pedagog- 
ical endeavour. Her textbook, A Practical Study of Argument, now in its seventh edition, is a model of lucid and engaging exposition, and contains a wealth of instructively analyzed examples. Her scholarly work in informal logic covers a wide range of topics and is marked by the clarity that characterizes her textbook. But it is not just through her textbook and scholarly publications that Trudy has contributed to informal logic. She has been an invaluable participant in numerous conferences on argumentation, and on these occasions, whether as a presenter or commentator, or in discussion periods, or over a drink and a meal, she has presented her views, and engaged with her fellow participants, in a vigorous but balanced way, always receptive to challenges, always courteous, always modest. She exemplifies to a high degree the virtues of thought and discourse that we who teach informal logic and critical thinking try to inculcate in our students.

In this paper, my concern is with her views on premise adequacy. More specifically, I will be concerned mainly with her views on one aspect of this subject, as I will now explain. Broadly speaking, to assess the premises of an argument for adequacy is to decide whether they are adequate as reasons for the argument's conclusion. One dimension of this question concerns what is said by the premises. Another dimension concerns the connection between what is said by the premises and what is said by the conclusion. Assessing premises on these dimensions requires, in each case, a criterion, or criteria, of adequacy. To assess the premises of an argument on the former dimension - that is, in terms of what is said by them - is to assess them independently of whether they are "properly connected" to the conclusion. Nevertheless, it seems to me that a decision as to what criterion is appropriate for this dimension of premise adequacy should be made with due regard to the fact that the premises of an argument serve as reasons for the conclusion, for it is precisely this fact that makes them be premises of an argument. My main concern will be with Govier's criterion for the adequacy of what is said by the premises of an argument. Her criterion is acceptability: for an argument to be cogent, its premises must be acceptable; that is, it must be "reasonable for the 


\section{Derek Allen}

person to whom the argument is addressed to accept them" (Govier $2010,116)$. On an alternative view, the appropriate criterion is truth: for an argument to be good, what is said by its premises must be true. Accepting a truth criterion, however, would not preclude also accepting an acceptability criterion, not as a criterion of whether an argument is a good argument in respect of what is said by its premises, but as a criterion for whether, in respect of what is said by its premises, an argument is a good argument relative to its audience.

\section{Perspectives}

"Premises are statements .... Basically, assessing premises is no different from assessing statements that appear in descriptions, reports, or explanations" (Govier 2010, 116). But we can assess statements for any number of different things, and from many different perspectives. For example, we can assess statements for their grammar (correct/incorrect), or for their literary merit (e.g., witty word play, as in "[t]o lose one parent, Mr. Worthing, may be regarded as a misfortune; to lose both looks like carelessness" (Wilde 1895)), or from the perspective of whether their public utterance should be legally permitted (as in the case of statements whose public utterance would count as the wilful promotion of hatred against an identifiable group). Thus, it needs to be decided from what perspective we should assess statements that are premises (more precisely, premises of arguments). Here it would be helpful to have a definition of an argument. Govier's textbook definition is the following:

An argument is a set of claims in which one or more of them - the premises - are put forward so as to offer reasons for another claim, the conclusion. (Govier 2010, 1)

Or, as she puts it a few pages later, 
In our sense of the word argument, a person has offered an argument if he or she has put forward premises in an attempt to support a conclusion. (Ibid., 8-9)

Govier's definition is a version of what Finocchiaro calls "the standard textbook definition" $(2005,295)$ and "the traditional definition" (ibid., 296). He cites Copi's definition of an argument as an example of a version of the standard textbook definition:

An argument, in the logician's sense, is any group of propositions of which one is claimed to follow from the others, which are regarded as providing support or grounds for the truth of that one. (Finocchiaro 2005, 295)

Finocchiaro comments:

$\mathrm{A}[\mathrm{n}]$... important feature of Copi's definition is the reference to the intention or purpose of the arguer.... [W] [Wen Copi says that the conclusion is claimed to follow from the premises, he is saying that the arguer claims this. And when he says that the premises are regarded as providing support or grounds for the conclusion, he is saying that the premises are so regarded by the arguer; that is, the arguer intends to use the premises to support the conclusion. In short, the purpose of the argument is to justify the conclusion by means of supporting reasons. (Finocchiaro 2005, 296)

Thus, "according to Copi's version of the traditional definition, an argument has [a] function" (ibid.). The same is true for Govier: the premises of an argument "are put forward so as to offer reasons for ... the conclusion" (italics added). Or, as she also says, "arguments are attempts to justify claims" $(2010,8)$.

But how is justification to be understood in this context? As Bonjour has noted, "the concept of justification is plainly a generic one-roughly, that of a reason or warrant of some kind meeting some appropriate standard. There are many specific varieties of justification actually in use and in principle as many as anyone cares to construct" (Bonjour 1985, 6). Some are species of justifi-

(C) Derek Allen. Informal Logic, Vol. 33, No. 2 (2013), pp. 116-142. 


\section{Derek Allen}

cation which can apply to beliefs. Bonjour gives an example in which he supposes that he has a close friend who has been accused of a horrible crime, and there is "substantial evidence" that he is guilty. Bonjour has no independent evidence concerning the matter, and his friend knows him "well enough that an insincere claim to believe in his innocence will surely be detected." If in these circumstances Bonjour can bring himself to believe in his friend's innocence, "it is surely plausible to say that there is a sense in which [he is] justified in so believing; indeed such a belief might well be regarded as obligatory. But the kind of justification in question is ... a kind of moral justification" (ibid.). It is not epistemic justification. Bonjour argues that

[t]he distinguishing characteristic of epistemic justification is ... its essential or internal relation to the cognitive goal of truth. It follows that one's cognitive endeavours are epistemically justified only if and to the extent that they are aimed at this goal, which means very roughly that one accepts all and only those beliefs which one has good reason to think are true. (Ibid.)

Would Govier say that arguments attempt to justify claims epistemically? This is to ask whether she would say that arguments attempt to show that there is good reason to believe that the claims in question (the arguments' conclusions) are true (or good reason to accept them as true), or, more precisely, that an argument attempts to show that there is good reason for its audience to believe that its conclusion is true (or to accept it as true). My answer will refer to elements of Govier's textbook explanation of when an argument is cogent, which is the following: an argument is cogent just in case its premises are $(\mathbf{A})$ acceptable, $(\mathbf{R})$ relevant to the conclusion, and (G) "provide adequate or good grounds for the conclusion" (2010, 87).

Govier has an account of when a statement is positively relevant to another statement, and I believe it can help us decide whether she would say that arguments attempt to justify claims (their conclusions) epistemically. She writes:

(C) Derek Allen. Informal Logic, Vol. 33, No. 2 (2013), pp. 116-142. 
A statement $A$ is positively relevant to another statement $B$ if and only if the truth of $A$ counts in favour of the truth of $B$. $(2010,148)$

and

A statement is positively relevant to the truth of another statement if and only if its truth would give some evidence or reason to support the truth of that other statement. That is, if the first statement were true, that would count in favor of the second one being true. (Ibid., 176)

As indicated above, Govier holds that an argument is cogent only if its premises are relevant to its conclusion - that is, only if they are positively relevant to the conclusion. Given her definition of positive (statemental) relevance, this means that an argument is cogent only if the truth of the premises would count in favour of the truth of the conclusion.

Now consider the following argument:

1. If the premises of argument $X$ are true, they count in favour of the truth of the conclusion of argument $X$.

2. The premises of argument $X$ are true.

Therefore,

3. The premises of argument $X$ count in favour of the truth of the conclusion of argument $\mathrm{X}$.

If premise 1 is true, then the premises of argument $X$ are positively relevant to the conclusion of argument X, by Govier's definition of positive relevance. Thus, if premise 2 is also true, then the premises of argument $X$ count in favour of the truth of the conclusion of argument X. Given Govier's definition of positive relevance and her view that for an argument to be cogent its premises must be positively relevant to the conclusion, she would say that if an argument's premises are both positively relevant to the conclusion and true, they count in favour of the truth of the conclusion, and so give "some evidence or reason" (Govier 2010, 176) to support its truth. 


\section{Derek Allen}

But "some evidence or reason" may not be sufficient "to make it rational to accept the conclusion" (Govier 2010, 87), in which case the argument will fail on Govier's "good grounds" condition for argument cogency. If, however, the argument satisfies that condition, and has acceptable premises, then it is cogent. These considerations suggest that Govier would indeed say that arguments attempt to justify claims (their conclusions) epistemically, by attempting to show that there is good reason to believe that their conclusions are true (or good reason to accept them as true). More precisely, she would say that an argument attempts to provide its audience with epistemic justification for believing that its conclusion is true, hence for accepting it as true.

Would she also say that we should assess an argument's premises from the perspective of whether the audience is epistemically justified in accepting them as true? Or is this directive at least compatible with her textbook views on premise adequacy?

I begin with a selection of those views.

(Ga) When we say that the premises of an argument are rationally acceptable, we mean that it would be reasonable for the person to whom the argument is addressed to accept them. If you are appraising the argument, then, for the moment at least, that person is you. (Govier 2010, 116; italics added)

(Gb) If you can accept - that is, believe - the premises of an argument without violating any standard of evidence or plausibility, its premises are rationally acceptable for you. (Ibid., 116; italics added)

Govier later gives a list of conditions on which premises are acceptable and a list of conditions on which premises are unacceptable.

\section{Acceptability conditions}

A premise in an argument is acceptable if any one of the following conditions is satisfied:

(C) Derek Allen. Informal Logic, Vol. 33, No. 2 (2013), pp. 116-142. 
1. It is supported by a cogent subargument.

2. It is supported elsewhere by the arguer or another person, and this fact is noted.

3 . It is known a priori to be true.

4. It is a matter of common knowledge.

5. It is supported by appropriate testimony. (That is, the claim is not implausible, the sources are reliable, and the claim is restricted in content to experience.)

6. It is supported by an appropriate appeal to authority.

A further circumstance is:

7. The premise is not known to be rationally acceptable, but can be accepted provisionally for the purpose of argument.

Point (7) is italicized to remind us that a conclusion supported by provisionally accepted premises is rendered provisionally acceptable - acceptable if those premises are acceptable. $(2010,128)$

\section{Unacceptability conditions}

1. One or more premises are refutable on the basis of common knowledge, a priori knowledge, or reliable knowledge from testimony or authority.

2. One or more premises are a priori false.

3. Several premises, taken together, produce a contradiction, so that the premises are explicitly or implicitly inconsistent.

4. One or more premises are vague or ambiguous to such an extent that it is not possible to determine what sort of evidence would establish them as acceptable or unacceptable.

5. One or more premises would not be rationally acceptable to any person who did not already accept the conclusion. 


\section{Derek Allen}

In this case, the argument begs the question or is circular. $^{1}(2010,135)$

Note that on neither list are the conditions relativized. But recall that according to Govier,

(Ga) When we say that the premises of an argument are rationally acceptable, we mean that it would be reasonable for the person to whom the argument is addressed to accept them. If you are appraising the argument, then, for the moment at least, that person is you. (2010, 116; italics added)

Thus, if Govier's acceptability and unacceptability conditions are to be consistent with $(\mathrm{Ga})$,they must be relativized to "the person to whom the argument is addressed," or to the argument's audience. This could be done as follows:

\section{Relativized acceptability conditions}

1. If a premise is supported by a subargument that is cogent for its audience by Govier's criteria, then it is reasonable for the audience to accept the premise as true, because the subargument succeeds in providing the audience with epistemic justification for believing that its conclusion is true, and hence for accepting it as true. ${ }^{2}$

2. This is also the case if it is reasonable for the audience to believe that the premise is (cogently) supported elsewhere by the arguer or by another person.

\footnotetext{
${ }^{1}$ Let "P" be a premise of the argument in virtue of which the argument is circular, and let " $\mathrm{S}$ " be the statement that is the conclusion. A person, W, might be epistemically justified in believing $\mathrm{P}$ for a reason, $\mathrm{R}$, other than $\mathrm{S}$, in which case $\mathrm{P}$ 's being rationally acceptable for $\mathrm{W}$ would not depend on his having already accepted S.

${ }^{2}$ This relativization, and those that follow, should also be relativized to a time (as in "cogent for its audience at time $t$ " or "at time $t$ it is reasonable for the audience to accept the premises as true"), but for the sake of simpler expression I do not do this here or in similar cases elsewhere in this paper. However, such relativizations are to be understood in similar cases throughout.
}

(C) Derek Allen. Informal Logic, Vol. 33, No. 2 (2013), pp. 116-142. 
3. If it is reasonable for the audience to believe that the premise is known a priori to be true, then it is reasonable for the audience to accept it as true.

4. This is also the case if it reasonable for the audience to believe that the premise is a matter of common knowledge.

5. If a premise is supported by testimony, the person who provides the testimony "tells us it is true" (Govier 2010, 121); thus, if it is reasonable for the audience to believe that the testimony is "appropriate," it is reasonable for the audience to accept the premise as true on the basis of the testimony.

(6) Similarly, if it is reasonable for the audience to believe that a premise, $\mathrm{P}$, is supported by an appeal to authority that by Govier's conditions is an appropriate appeal, then it is reasonable for the audience to accept the premise as true on that basis, for those conditions are the following: (a) Expert $\mathrm{X}$ has asserted $\mathrm{P}$; (b) $\mathrm{X}$ is a reliable and credible person in this context; (c) P falls within area of specialization $\mathrm{K}$, which (d) is a genuine area of knowledge; (e) $\mathrm{X}$ is an expert, or authority, in $\mathrm{K}$, and (f) the experts in K agree about $\mathrm{P}$ (Govier 2010, 126).

\section{Relativized unacceptability conditions}

1. If an argument's audience is justified in believing that a premise of the argument is "refutable on the basis of common knowledge, a priori knowledge, or reliable knowledge from testimony or authority" (ibid., 135), then the audience cannot reasonably accept the premise as true, for " $[\mathrm{t}] \mathrm{o}$ refute a claim is to show that it is false" (Ibid., 131).

2. If the audience is justified in believing that a premise of the argument is a priori false, then it cannot reasonably accept the premise as true.

3. If it is reasonable for the audience to believe that "several premises [of the argument], taken together, produce a contradiction, so that the premises are explicitly or implicitly inconsistent" (ibid.), then it is not the case that the audience can reasonably accept all of the premises as true. 


\section{Derek Allen}

4. If it is reasonable for the audience to believe that a premise of the argument is "vague or ambiguous to such an extent that it is not possible to determine what sort of evidence would establish [it] as acceptable or unacceptable" (ibid.), then the audience cannot reasonably accept it as true.

5. If the audience is justified in believing that a premise of the argument "would not be rationally acceptable to any person who did not already accept the conclusion" (ibid.) then it is not reasonable for the audience to accept that premise as true.

These relativizations of Govier's acceptability and unacceptablility conditions speak of its being reasonable, or not reasonable, for the audience of an argument to accept the premises of the argument as true. The very fact that they can be thus relativized is reason to think that Govier would have no objection to our construing her acceptability requirement for premise adequacy as the requirement that for an argument to be cogent by her criteria it must be reasonable for the audience to accept the argument's premises as true.

Another reason is this. If an argument is cogent for an audience by Govier's criteria, then it is reasonable for the audience to believe that if the argument's premises are true they count in favour of the conclusion and so are positively relevant to the conclusion. If, then, it is also reasonable for the audience to accept the argument's premises as true, and to believe that they provide sufficient reason to make it rational to accept the argument's conclusion, then, by Govier's criteria, the argument is cogent for the audience.

A final reason. Govier says that when assessing premises, "[w]e have to think about the evidence that we have in favour of these claims and how likely they are to be true in the light of this evidence" (2010, 116-17; italics added).

I conclude that Govier's acceptability requirement for premise adequacy can plausibly be interpreted as the requirement that for an argument to be cogent by her criteria, it must be reasonable for the audience to accept the argument's premises as true. 
I began this section by saying that it needs to be decided from what perspective we should assess statements that are premises (more precisely, premises of arguments). I believe that we are now in a position to give an answer to this question that is compatible with Govier's textbook views on premise adequacy: we should assess the premises of an argument from the perspective of whether the audience is epistemically justified in accepting them as true.

At the outset of this section I also said that statements can be assessed from a variety of perspectives. Similarly, statements can be assessed for acceptability or unacceptability from a variety of perspectives. For example, a statement may be found acceptable/unacceptable relative to (culturally variable) norms of social propriety. From the perspective of some such norm, a statement may be judged acceptable or unacceptable depending on whether it is considered to be rude or offensive or defamatory or harmful or obscene or blasphemous. (It may be replied: what is considered acceptable or unacceptable from the perspective of one or another such norm is the utterance of the statement. To be sure, but the assessment will depend on what is said by the statement uttered.) What, then, is the appropriate perspective from which to assess for acceptability/unacceptability statements that are the premises of arguments? If arguments are attempts to provide epistemic justification for claims (their conclusions), as I have argued Govier would say they are, then the appropriate perspective is that of whether it would be reasonable for a person addressed by an argument to accept its premises insofar as her "cognitive endeavors" were aimed at truth (Bonjour 1985, 8). I believe that Govier would find this acceptable.

\section{Why not "true"?}

I will now consider three arguments that Govier makes against the view that a good argument must have true premises.

(C) Derek Allen. Informal Logic, Vol. 33, No. 2 (2013), pp. 116-142. 


\section{Derek Allen}

\subsection{The unacceptable consequence argument}

In (1987), Govier writes that

logical tradition ... insisted that in a sound argument, the premises were true. Whatever anybody believes, if the premises are true, they are just true, and if the argument is, in addition, valid, it is sound in an absolute and timeless sense. But the problem is that if we stipulate that people should be convinced only by those arguments that have true premises, we would in effect be stipulating that in many times and places, people should not be convinced by arguments at all. In fact, it would be a very tough epistemological task to show that we ourselves should often be convinced by arguments on this kind of model. $(1987,280)$

Govier speaks here of a sound argument as traditionally understood in logic, but presumably she would have said at the time she wrote (1987) that her stricture applied to any conception of a good argument with a true-premises requirement. Accordingly, I believe that in the above passage she is making an argument that can be reconstructed as follows:

1. To take the view that for an argument to be good it must have true premises is to stipulate that people should be convinced only by those arguments that have true premises.

2. In many times and places all the arguments that people hear and read have false premises.

Therefore,

3. To take the view that for an argument to be good it must have true premises is in effect (that is, for practical purposes) to stipulate that in many times and places people should not be convinced by arguments at all.

4. This is an unacceptable consequence of taking that view.

Therefore,

5. We should not take it.

(C) Derek Allen. Informal Logic, Vol. 33, No. 2 (2013), pp. 116-142. 
The second premise of this argument is not plausible. A plausible alternative would be

2a. In many times and places, people hear and read arguments whose premises express widespread false beliefs about the topics concerned.

But if (2) is replaced by (2a), then (3) should be replaced by a claim to the effect that

3a. To take the view that for an argument to be good it must have true premises is in effect (that is, for practical purposes) to stipulate that in many times and places there are topics on which people (living then and there) hear and read arguments by which they should not be convinced.

If making this stipulation is (in effect) a consequence of taking the view that for an argument to be good it must have true premises, is it an unacceptable consequence? (This question is prompted by premise 4 in my reconstruction of Govier's argument.) The issue here is whether the view that people should not be convinced by arguments with false premises is unacceptable. Govier's argument provides no reason to think that it is. (It is worth adding, I believe, that to hold that people should not be convinced by arguments with false premises is compatible with holding that people who are convinced by an argument which, unbeknownst to them, has false premises, and by which, ex hypothesi, they should therefore not be convinced, may be beyond epistemic reproach, for they may be epistemically justified in believing that the argument's premises are true and that the argument is not otherwise defective. $)^{3}$

${ }^{3}$ I am indebted to an anonymous reader of an earlier version of this paper for comments that led me to revise my initial reconstruction of what I have called Govier's "unacceptable consequence" argument and to abandon my initial assessment of the argument and replace it with the commentary given above. To be more specific, comments by the reader guided my wording of premise 2 , and, to a lesser degree, my wording of intermediate conclusion 3 . The comment I make

(C) Derek Allen. Informal Logic, Vol. 33, No. 2 (2013), pp. 116-142. 


\section{Derek Allen}

\subsection{A pragmatic argument}

The traditional account of soundness might be preserved as a kind of regulative ideal, but standards of argument appraisal that are intended to give real practical guidance will have to move from truth of premises to acceptability. (Govier, 1987, 280)

I take it that this passage can be interpreted as an elliptical argument and that the complete argument could be standardized as follows:

1. Standards of argument appraisal that are intended to give real practical guidance will have to move from truth of premises to acceptability.

2. Standards of argument appraisal should be intended to give real practical guidance.

Therefore,

3. Standards of argument appraisal should move from truth of premises to acceptability.

If we wish to provide "standards of argument appraisal that are intended to give real practical guidance," we must first have an account of when an argument is good or cogent. In (1992), Govier presents six accounts each of which specifies a set of conditions that the account takes to be individually necessary and jointly sufficient for argument cogency. Each of the accounts gives some practical guidance for argument appraisal, simply because we can tell from each what must be ascertained, on that account, for the purpose of appraising an argument for cogency: ascertaining that the argument fails on one of the conditions will suffice for a negative appraisal, while ascertaining that it satisfies each of the conditions will be necessary and sufficient for a positive appraisal. To be sure, the accounts don't tell us when their conditions are satisfied,

on premise 2 ("not plausible") was made by the reader; my "plausible alternative" (2a) is based on a comment the reader made, as is part of my wording of 3a.

(C) Derek Allen. Informal Logic, Vol. 33, No. 2 (2013), pp. 116-142. 
or how to go about deciding, in a particular case, whether their conditions are satisfied. But that is not their business. An account of when an argument is good (cogent) can, however, be supplemented by a specification of conditions under which the account's conditions for argument goodness (cogency) are satisfied, and this may be done with the intention of giving "real practical guidance" for argument appraisal.

Govier herself does exactly this in her textbook (2010). As we know, on her account, an argument is cogent if and only if its premises are (A) acceptable, and (R) relevant to the conclusion, and $(\mathbf{G})$ "provide adequate or good grounds for the conclusion" (Govier 2010, 87). Having listed these conditions, she expands on $\mathbf{R}$ and $\mathbf{G}$ by identifying and explaining four ways in which the premises of an argument may be properly connected to its conclusion. She then has a section on using the ARG conditions to evaluate arguments, with a subsection for each on failing on that condition followed by a subsection on satisfying all three conditions. The next chapter ("Premises: What to Accept and Why") lists and discusses her acceptability and unacceptability conditions.

A similar approach would be possible in the case of an account on which argument goodness (cogency) requires true premises. One might supplement such an account with "a criterion or test of truth, that is, a practical guide for telling which propositions are true" (Goldman, 1999, 41). To provide such a guide "is the task of ... the theory of evidence, justification, or truth determination. These theories try to say when it is appropriate to accept a proposition as true, or how to go about determining the truth or falsity of a proposition" (ibid.; italics added). I doubt that Govier would deny the possibility of supplementing with a theory of truth determination an account of argument goodness (cogency) that has a truepremises requirement.

\subsection{Govier's necessary and sufficient conditions argument}

Truth, Govier believes, "is neither necessary nor sufficient for premise adequacy" (1992, 395). She continues: 


\section{Derek Allen}

It is not necessary, because if one person argues with another using as his premises only claims that both accept, he can often convince the other of the conclusion by doing so. And if that other's acceptance of the premissory claims is rational, as acceptance often is, even when those claims turn out not to be true, to reason from it is surely rational as well. We now think that in past ages, many scientific beliefs were false. Yet we think that scientists and others who reasoned from these beliefs to further beliefs, whether in theoretical or practical contexts, determined their decisions and beliefs in a rational and responsible way. An important tool in doing so was that of argument. To say that for scientists and intellectuals of past ages, no argument was ever cogent, because the premises they used, though rationally acceptable for them, were not true, is just unreasonable. It is also incorrect, in fact, to see the truth of an argument's premises as a sufficient condition for their epistemic adequacy. What counts is not whether they are true, but whether the audience has good reasons to believe them true, such that those good reasons are independent of that audience's acceptance of the conclusion. (Ibid., 395-96)

If truth is not necessary for premise adequacy, then a premise of an argument can be adequate even if it is false. But if

(TR) For an argument to be good, it must have true premises

is correct, then a premise of an argument is not adequate if it is false, for its falseness prevents the argument from being good. Thus, an adherent of (TR) is committed to the view that truth is necessary for premise adequacy. Accordingly, one way of testing Govier's reasons for holding that truth is not necessary for premise adequacy is to consider whether an adherent of (TR) is free to accept the claims that constitute her reasons-free in the sense that he can accept them consistently with endorsing (TR).

Govier argues that truth is not necessary for premise adequacy partly on the following grounds: 
(G1) If one person argues with another using as his premises only claims that both accept, he can often convince the other of the conclusion by doing so;

and

(G2) If that other's acceptance of the premissory claims is rational, as acceptance often is, even when those claims turn out not to be true, to reason from it is surely rational as well.

(G1) is an empirical claim, and an adherent of (TR) can accept it.

She can also accept

(G2a) Acceptance by an arguer's intended audience of the arguer's premissory claims is often rational even when those claims turn out not to be true,

for she can grant that the intended audience may have strong evidence that the claims are true and (rationally) accept them for this reason.

An adherent of (TR), as such, is also free to accept

(G2b) If acceptance by an arguer's intended audience of the arguer's premissory claims is rational, for the arguer to reason from it is surely rational as well.

In particular, his reasoning from his intended audience's acceptance of the claims is not prevented from being rational even if the claims are false, provided that the audience's acceptance of the claims is rational in the sense that the audience is epistemically justified in accepting the claims as true and provided that the arguer himself is epistemically justified in accepting them as true.

Next, 


\section{Derek Allen}

(G3) To say that for scientists and intellectuals of past ages, no argument was ever cogent, because the premises they used, though rationally acceptable for them, were not true, is just unreasonable.

Can an adherent of (TR) accept (G3)? In (G3), Govier is assuming that someone who has a true-premises requirement for argument cogency would say: "for scientists and intellectuals of past ages, no argument was ever cogent, because the premises they used, though rationally acceptable for them, were not true." But to have a truepremises requirement for argument cogency is compatible with allowing that even if an argument has false premises it may be "cogent for" person $\mathrm{X}$ in what I take to be the relevant sense, namely in the sense that $\mathrm{X}$ is epistemically justified in believing the argument to be cogent tout court.

I conclude that an adherent of (TR) is free to accept each of the claims that Govier makes to show that truth is not a necessary condition for premise adequacy.

Indeed, she later makes a remark that, as it stands, is tantamount to conceding that, as (TR) claims, for an argument to be good, it must have true premises. She considers an invalid argument which, if amended as she thinks a deductivist would propose it should be, would become two deductively valid arguments, and she says that on one version of these arguments they "don't justify their conclusion because they each contain a false premise" (Govier 1992, 400). If an argument's having a false premise prevents it from justifying its conclusion, then, on the assumption that a premise is true if it is not false, truth is a necessary condition for premise adequacy. However, there is a rejoinder that Govier could make. In the example she considers, one of the false premises is "you should do everything you promise to do"; the other false premise is "you should never get in trouble." Govier might say that these premises are obviously false and for this reason unacceptable (as true), and 
that it is because they are unacceptable (as true) that the arguments in question don't (epistemically) justify their conclusions. ${ }^{4}$

An adherent of (TR) would claim that the truth of an argument's premises is necessary for their adequacy, but would not need to claim that it is sufficient. But this is not relevant for the purpose of assessing Govier's reasons for thinking that truth is not sufficient for premise adequacy. What is relevant is the following view:

(Q) For an argument to be good, being true is the only condition that its premises must satisfy in order to be adequate independently of whether they are "properly connected" to the conclusion.

For an account of argument goodness that subscribes to (Q), truth is sufficient for the premises of an argument to be adequate independently of whether they are "properly connected" to the conclusion.

For Govier,

(G4) It is incorrect to see the truth of an argument's premises as a sufficient condition for their epistemic adequacy;

and

(G5) What counts [for their epistemic adequacy] is not whether they are true, but whether the audience has good reasons to believe them true, such that those good reasons are independent of that audience's acceptance of the conclusion.

Here Govier speaks of "epistemic adequacy" rather than of premise adequacy. An adherent of (Q) can cheerfully endorse (G4) and (G5), given that Q's account of what it is for an argument to be

\footnotetext{
${ }^{4}$ This rejoinder is a minor variation on one suggested to me by the anonymous reader of an earlier version of this paper.
}

(C) Derek Allen. Informal Logic, Vol. 33, No. 2 (2013), pp. 116-142. 


\section{Derek Allen}

good in respect of its premises (considered independently of whether they are "properly connected" to the conclusion) is not an epistemic account. Or is Govier assuming that premise adequacy always is epistemic adequacy? This would be to beg the question of whether there is a viable non-epistemic account of premise adequacy (perhaps one that would complement an epistemic account).

\section{Having it both ways}

Govier's A condition for argument cogency (acceptable premises) is epistemic. Her relevance $(\mathbf{R})$ and sufficient reason $(\mathbf{G})$ conditions are not epistemic. $\mathbf{R}$ does not require the satisfaction of an epistemic condition such as: an argument is cogent for its audience only if the audience is epistemically justified in believing that the premises are relevant to the conclusion. Rather, $\mathbf{R}$ requires that the premises be relevant to the conclusion. $\mathbf{G}$ does not require the satisfaction of an epistemic condition such as: an argument is cogent for its audience only if the audience is justified in believing that the premises provide "adequate or good grounds for the conclusion" (Govier 2010, 87). Rather, $\mathbf{G}$ requires that the premises provide adequate or good grounds for the conclusion. Thus, Govier's conception of a cogent argument is not entirely epistemological, but it is partly epistemological (condition A).

Feldman has defined a conception of a good argument that is also partly epistemological, but it is more epistemological than Govier's conception of a cogent argument:

An argument is a good argument relative to person $\mathrm{S}$ if and only if

(i) $\mathrm{S}$ is justified in believing the conjunction of all the premises of the argument,

(ii) the argument is either valid or inductively strong, and

(iii) $\mathrm{S}$ is justified in believing that the premises are "properly connected" to the conclusion, and 
(iv) the argument is not defeated for $\mathrm{S}^{5}$.

Goldman thinks that an epistemological sense of good argument is "extremely important," but that so is what he calls a "logical" notion of good argument (Goldman 1995, 56-7), of which he gives the following as a "viable" example:

An argument is a good argument if and only if (i) the relation between its premises and conclusion is either that of deductive validity or strong inductive support, and (ii) it contains only true premises. (Goldman 1995, 56)

If an epistemological conception of good argument and a "logical" conception of good argument are both extremely important, then presumably a theory of argument ought to include both. The two conceptions could be integrated in the following way:

An argument is a good argument relative to person $\mathrm{S}$ if and only if $\mathrm{S}$ is epistemically justified in believing that it satisfies conditions $\mathrm{C} 1 \ldots \mathrm{Cn}$, where these are the theory's conditions for when an argument is a good argument.

Further, the theory could specify conditions on which a person is, or is not, justified in holding this belief, and could provide guidelines for argument appraisal.

On the subject of premise adequacy, the theory could hold that

(1) For an argument to be good, its premises must be true, and

5 (Goldman 1995, 57; Feldman 1994). Goldman does not include (iv) in his list of Feldman's conditions, for a reason he gives in a footnote at p. 57.

(C) Derek Allen. Informal Logic, Vol. 33, No. 2 (2013), pp. 116-142. 


\section{Derek Allen}

(2) For an argument to be good relative to its audience, the audience must be epistemically justified in accepting the argument's premises as true.

Further, the theory might include appropriately relativized versions of Govier's acceptability and unacceptability conditions for premise adequacy (conditions on which a person is, or is not, epistemically justified in accepting the premises of an argument as true). It might also include practical guidelines for premise appraisal, and these could include guidelines that Govier provides in (2010).

\section{5. "Proposition A counts in favour of proposition B"}

Assume "the traditional definition of a proposition, [on which] ... every proposition must be either true or false" (Woods, Irvine, Walton, 2004, 170). Then propositions A and B are each true if not false. On Govier's account of positive (statemental/propositional) relevance, if $\mathrm{A}$ is positively relevant to $\mathrm{B}$, then if $\mathrm{A}$ is true this is sufficient for A to count in favour of (the truth of) B. It is not a consequence of Govier's account of positive relevance that if $\mathrm{A}$ is positively relevant to $\mathrm{B}$ then the truth of $\mathrm{A}$ is necessary for $\mathrm{A}$ to count in favour of (the truth of) $\mathrm{B}$. But this does not mean that the truth of A is not necessary for A to count in favour of (the truth of) B. Is it? Consider the following example:

(1) X's fingerprints are on the weapon that was used to kill Y.

(2) It was X who killed Y.

If (1) is true, it counts (at least to some degree) in favour of the truth of (2). But suppose that (1) is false. Does it still count in favour of the truth of (2)? Can it be the case that the claim that X's fingerprints are on the weapon that was used to kill Y counts in favour of the truth of the claim that it was X who killed Y even if X's fingerprints are not on the weapon that was used to kill Y? Surely not. Can a false proposition count in favour of the (the truth of) an- 
other proposition? I don't think so. This is an intuition of mine; I don't know of a way to support it except by means of examples such as the one I have just given. If it is correct, then a nonepistemological account of argument goodness must hold that truth is a necessary condition for premise adequacy (assuming that the premises and conclusion of an argument are propositions as traditionally defined), hence that (on this same assumption) an argument is a good argument only if its premises are true.

\section{Probative adequacy}

Recall that for Govier a cogent argument is "epistemically and logically adequate" (1992, 393). In addition to epistemic adequacy and logical adequacy, however, there is probative adequacy. At any rate, this is a further form of adequacy if logical adequacy is understood as Govier understands it in (1992), namely as a condition on the connection ("inferential link") between an argument's premises and its conclusion.

If an argument has probative adequacy, its premises count in favour of (the truth of) its conclusion, and so (by my above intuition) its premises must be true. (I agree with Kelley that "false premises don't prove anything" (Kelley 1988, 94). This is a case of a fortiori if a false proposition cannot count in favour of (the truth of) another proposition.)

An argument is, or is not, probatively adequate relative to a standard of proof. Standards of proof are context-variable. They may be institutional standards or standards applied by individuals in certain non-institutional contexts. The criminal law standard of proof beyond reasonable doubt is an example of an institutional standard of proof.

I will conclude with an example of a criminal case and relate it to Govier's account of premise adequacy and to the view that a good argument must have true premises.

In a Canadian criminal trial held in 1959, a judge and jury "found Steven Truscott guilty of the murder of Lynne Harper and 


\section{Derek Allen}

sentenced him to hang. The sentence was later commuted to life imprisonment. His attempts to appeal the conviction failed" (Truscott 2007). The conviction was referred to the Supreme Court of Canada in 1966, and upheld. In 2004, following a further request by Truscott, the Minister of Justice referred his conviction to the Ontario Court of Appeal, because the Minister was satisfied, in the light of fresh evidence, that there was a reasonable basis to conclude that a miscarriage of justice had occurred in the case.

A critical issue at the trial was the time of Harper's death. The Crown's argument on this issue can be reconstructed as follows:

1. If Harper died between 7 and 8 p.m., then Truscott must have killed her, whereas if she was killed after 8 p.m. then he was not the person who killed her.

2. Harper died between 7 and 8 p.m.

Therefore it must be the case that,

3. Truscott killed her.

The jury was satisfied beyond a reasonable doubt, in light of the evidence available to it, that 1 and 2 were true, and hence that 3 was true, and so found Truscott guilty.

The Ontario Court of Appeal had new evidence available to it with respect to the truth or falsity of 2 . The synopsis of the Truscott reference summarizes part of the court's reasoning as follows:

The court concludes that the fresh evidence relating to the time of death, considered in the context of the entirety of the evidence, could reasonably be expected to have caused the jury to at least have a reasonable doubt that Lynne Harper died before 8 p.m. If the jury had [had] a reasonable doubt on this factual issue, it could not have convicted the appellant. The results of the prior proceedings therefore could reasonably be expected to have been different if this fresh evidence had been available. The court's determination to admit this fresh evidence means that as a matter of law the verdict cannot stand. The conviction must be quashed as a miscarriage of justice. (Truscott 2007)

(C) Derek Allen. Informal Logic, Vol. 33, No. 2 (2013), pp. 116-142. 
Govier's acceptability account of premise adequacy can easily accommodate the issue of whether the Crown's argument (as reconstructed above) met the relevant standard of proof. Given the evidence available to the 1959 jury, it was reasonable for the jury to accept premise 2 in the Crown's argument. But had the subsequent "fresh evidence relating to the time of death" been available to the jury, this "could reasonably be expected to have caused the jury to at least have a reasonable doubt that Lynne Harper died before 8 p.m.," in which case, given that the standard of proof that the Crown had to meet was proof beyond reasonable doubt, it would not have been reasonable for the jury to accept premise 2 in the Crown's argument. Consequently, it would have been reasonable for the jury to conclude that the Crown had not established beyond reasonable doubt that Truscott killed Harper.

Adherents of the view that a good argument must have true premises can accept all this, provided at least that "accepting premise 2" is understood as accepting it as true. But they can also endorse a non-epistemic condition of probative adequacy on which an argument whose premises are propositions as traditionally defined is probatively adequate (in any context of proof) only if its premises are true. If premise 2 in the Crown's argument was false (as the subsequent "fresh evidence" suggested it was), then the Crown's argument did not satisfy this condition of probative adequacy, and so, by this measure, it did not prove that Truscott killed Harper.

\section{References}

Bonjour, L. (1985). The Structure of Empirical Knowledge. Cambridge, MA and London: Harvard University Press.

Feldman, R. (1994). “Good arguments.” In F.F. Schmitt (Ed.), Socializing Epistemology: The Social Dimensions of Knowledge. Lanham, MD: Rowman \& Littlefield.

Finocchiaro, M.A. (2005). Arguments about Arguments. Cambridge: Cambridge University Press.

(C) Derek Allen. Informal Logic, Vol. 33, No. 2 (2013), pp. 116-142. 


\section{Derek Allen}

Goldman, A. (1995). "Argumentation and interpersonal justification." In F.H. van Eemeren, et al. (Eds.), Proceedings of the Third ISSA Conference on Argumentation, Vol. 1, 53-61. Amsterdam: SicSat.

Goldman, A. (1999). Knowledge in a Social World. Oxford: Clarendon Press.

Govier, T. (1987). "The Social Epistemology of Argument." Problems in Argument Analysis and Evaluation. Dordrecht: Foris.

Govier, T. (1992). "What is a good argument?" Metaphilosophy 23(4), 393-409.

Govier, T. (2010). A Practical Study of Argument, $7^{\text {th }}$ ed. Belmont, CA: Wadsworth.

Kelley, D. (1988). The Art of Reasoning. New York, London: Norton.

Truscott (2007). Synopsis of Reference re: R. v. Steven Murray Truscott. Ontario Court of Appeal 575. August 28, 2007. Docket: C4276.

Wilde, O. (1895). The Importance of Being Earnest, Act 1.

Woods, J. and Irvine, A. and Walton, D. (2004). Critical Thinking, Logic and the Fallacies, $2^{\text {nd }}$ ed. Toronto: Pearson-Prentice Hall. 